\title{
Karyotypes of Dremomys pernyi and D. pyrrhomerus (Rodentia: Sciuridae) from China
}

\section{$\operatorname{AUTHOR}(\mathrm{S})$ :}

Motokawa, Masaharu; Cong, Haiyan; Kong, Lingming; Harada, Masashi; Wu, Yi; Li, Yuchun

\section{CITATION:}

Motokawa, Masaharu ...[et al]. Karyotypes of Dremomys pernyi and D. pyrrhomerus (Rodentia: Sciuridae) from China. Mammal Study 2017, 42(1): 45-49

\section{ISSUE DATE:}

2017-03-01

URL:

http://hdl.handle.net/2433/250821

\section{RIGHT:}

(c) The Mammal Society of Japan; The full-text file will be made open to the public on 1 March 2018 in accordance with publisher's 'Terms and Conditions for Self-Archiving' 


\title{
Karyotypes of Dremomys pernyi and D. pyrrhomerus (Rodentia: Sciuridae) from China
}

\author{
Authors: Motokawa, Masaharu, Cong, Haiyan, Kong, Lingming, \\ Harada, Masashi, Wu, Yi, et al.
}

Source: Mammal Study, 42(1) : 45-49

Published By: Mammal Society of Japan

URL: https://doi.org/10.3106/041.042.0105

BioOne Complete (complete.BioOne.org) is a full-text database of 200 subscribed and open-access titles in the biological, ecological, and environmental sciences published by nonprofit societies, associations, museums, institutions, and presses.

Your use of this PDF, the BioOne Complete website, and all posted and associated content indicates your acceptance of BioOne's Terms of Use, available at www.bioone.org/terms-of-use.

Usage of BioOne Complete content is strictly limited to personal, educational, and non - commercial use. Commercial inquiries or rights and permissions requests should be directed to the individual publisher as copyright holder.

BioOne sees sustainable scholarly publishing as an inherently collaborative enterprise connecting authors, nonprofit publishers, academic institutions, research libraries, and research funders in the common goal of maximizing access to critical research. 


\title{
Karyotypes of Dremomys pernyi and D. pyrrhomerus (Rodentia: Sciuridae) from China
}

\author{
Masaharu Motokawa ${ }^{1}$, Haiyan Cong ${ }^{2}$, Lingming Kong ${ }^{2}$, Masashi Harada ${ }^{3}$, Yi Wu ${ }^{4}$ \\ and Yuchun $\mathrm{Li}^{2}$,* \\ ${ }^{1}$ The Kyoto University Museum, Kyoto University, Kyoto 606-8501, Japan \\ ${ }^{2}$ Marine College, Shandong University, Weihai 264209, China \\ ${ }^{3}$ Laboratory Animal Center, Graduate School of Medicine, Osaka City University, Osaka 545-8585, Japan \\ ${ }^{4}$ College of Life Sciences, Guangzhou University, Guangzhou 510006, China
}

\begin{abstract}
Karyotypes of Dremomys pernyi from Kanding, Sichuan Province, China and $D$. pyrrhomerus from Nanling, Guangdong Province, China were examined. The karyotype of $D$. pernyi was of $2 \mathrm{n}=40$ and $\mathrm{FNa}=72$, while that of $D$. pyrrhomerus was of $2 \mathrm{n}=38$ and $\mathrm{FNa}=70$. Karyotype of $D$. pernyi from Kanding was different in $2 \mathrm{n}$ and FNa from reported karyotype of conspecific population from Taiwan, and it is suggested that the Taiwan population represents a distinct species $D$. owstoni from $D$. pernyi. The difference between karyotypes of $D$. pernyi and $D$. pyrrhomerus may involve at least a Robertsonian rearrangement and a heterochromatin addition.
\end{abstract}

Key words: Dremomys, karyotype, Sciuridae, Taiwan, taxonomy.

The genus Dremomys is plain long-nosed squirrels of Asia comprising six species (Thorington and Hoffmann 2005; Thorington et al. 2012). Five species, including D. pyrrhomerus (Thomas, 1895), D. rufigenis (Blanford, 1878), D. pernyi (Milne-Edwards, 1867), D. gularis Osgood, 1932, and D. lokriah (Hodgson, 1836), are distributed in China and Indochina region, while another species $D$. everetti is known from Borneo (Hoffmann and Smith 2008; Thorington et al. 2012). Species taxonomy and boundary is still unclear, especially among $D$. pyrrhomerus, D. rufigenis, and D. pernyi. Oshida et al. (2003) reported a karyotype of $D$. pernyi from Taiwan and discussed the karyotype differences between Taiwan and Yunnan populations reported by Wang et al. (1980), and noted that the Taiwan D. pernyi population is more similar to $D$. rufigenis from Vietnam with a diploid chromosome number (2n) of 38 and a fundamental number of autosomal arms (FNa) of 68, reported by Nadler and Hoffmann (1970). Although $2 \mathrm{n}$ is similar between $D$. pernyi from Taiwan and D. rufigenis from Vietnam, the karyotypes were found to be different in the published figures; there were seven subtelocentric pairs in Vietnam D. rufigenis population, and nine pairs in Taiwan $D$. pernyi population. Among Dremomys species, the taxonomic status of $D$. pyrrhomerus has also been confused; it had been considered conspecific with D. rufigenis (e.g., Corbet and Hill 1992). While, these two species are currently considered different species due to their sympatric distribution (Thorington and Hoffmann 2005; Hoffmann and Smith 2008), but their distribution boundary between species is still unclear. Karyological study of Dremomys species is expected for the revision of species taxonomy of the genus. In the present study, we report karyotypes of two Dremomys species from China and discuss the taxonomic implications of $D$. pernyi, D. pyrrhomerus, and $D$. rufigenis.

\section{Materials and methods}

One male specimen of $D$. pernyi (G10138) was collected in August 2010, from Kangding, Ganzi Tibetan Autonomous Prefecture, Sichuan Province, China; and one male specimen of $D$. pyrrhomerus (G12185) was collected in August 2012, from Nanling, Guangdong Province, China (Fig. 1). The voucher specimens were deposited in the Key Laboratory of Conservation and

*Towhom correspondence should be addressed.E-mail:_l_yuchun@sdu.edu.cn 


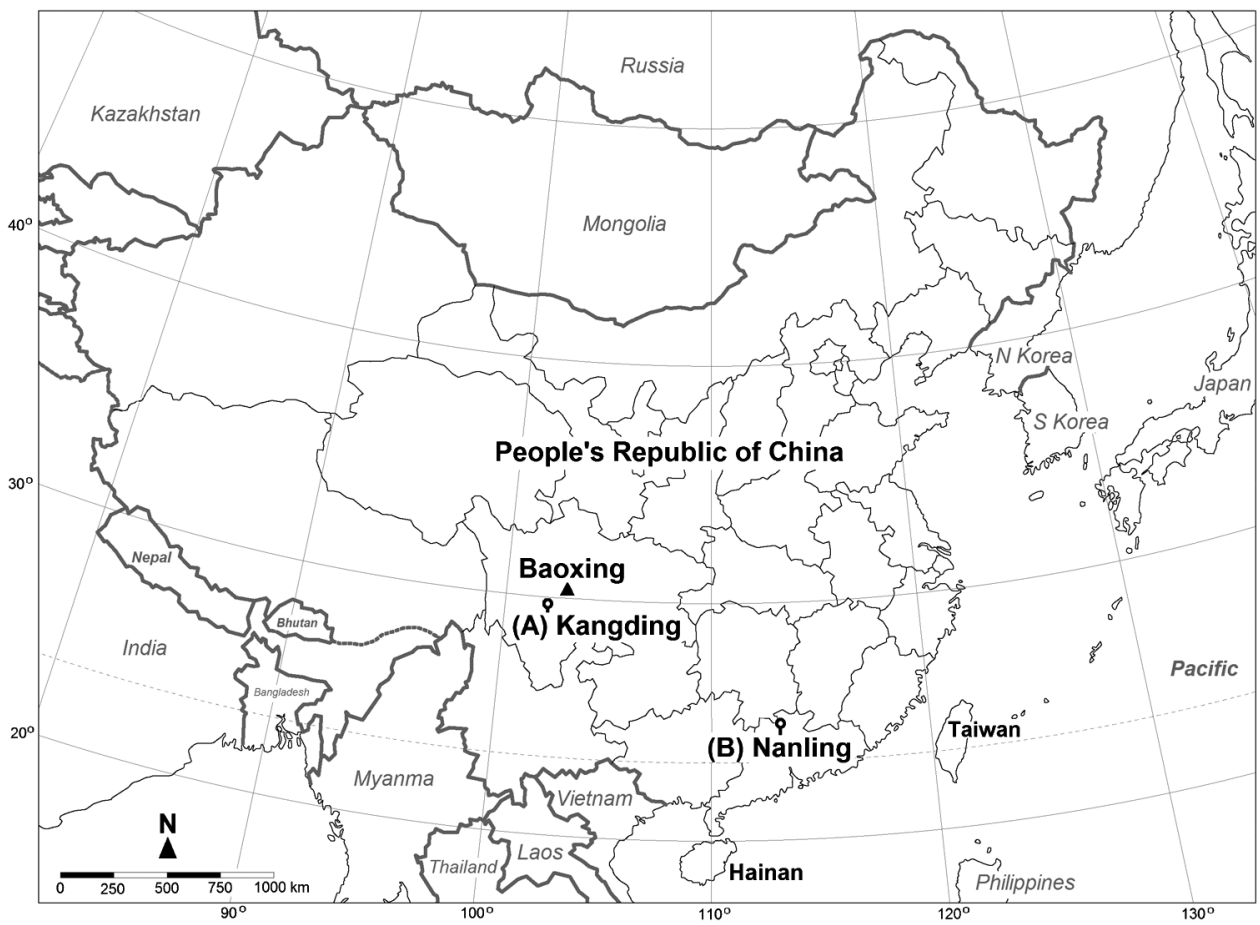

Fig. 1. Map of China showing the sampling localities of Dremomys pernyi (A) and D. pyrrhomerus (B).

Application in Biodiversity of South China, Guangzhou University (G10138) and Marine College, Shandong University, Weihai (G12185).

Cytological preparations were made from tail and/or lung tissue culture cells using the standard air-drying method as described by Harada and Yosida (1978). G-band and C-band stainings were accomplished with the methods of Seabright (1971) and Sumner (1972), respectively. Terminology for chromosomes follows Levan et al. (1964): metacentric, submetacentric, subtelocentric, and acrocentric. The $2 \mathrm{n}$ and $\mathrm{FNa}$ values for each species were calculated.

\section{Results}

The karyotype of $D$. pernyi (Fig. 2) was of $2 n=40$ $(\mathrm{FNa}=72)$ chromosomes consisting of eight large- to small-sized meta- or submetacentric pairs (nos. 1-8), nine large- to small-sized subtelocentric pairs (nos. 9-17), and two medium- to small-sized acrocentric pairs (nos. 18-19) in autosomes and a medium-sized submetacentric $\mathrm{X}$ chromosome and a small-sized subtelocentric Y chromosome. In an acrocentric pair (no. 19), there was secondary constriction at the proximal region of long arms as shown with an arrow (Fig. 2A). Short arm of a subtelocentric pair (either of nos. 10-13) was stained with C-band and considered heterochromatic (Fig. 2C, shown with an arrow). In addition, the autosome pairs of nos. 1-3 and no. 9 had small centromeric C-bands; the short arms of pairs 15-17 were entirely heterochromatic; telomeric C-bands were detected either on the short arm or the long arm, or on both arms of pairs nos. 1-4, 9, 18 and 19; the Y chromosome was entirely heterochromatic (Fig. 2C).

The karyotype of D. pyrrhomerus (Fig. 3) was of $2 \mathrm{n}=$ $38(\mathrm{FNa}=70)$ chromosomes consisting of 12 large- to small-sized meta- or submetacentric pairs (nos. 1-12), five large- to small-sized subtelocentric pairs (13-17), and one small-sized acrocentric pair (no. 18) in autosomes, and a medium-sized submetacentric $\mathrm{X}$ chromosome and a small-sized subtelocentric $\mathrm{Y}$ chromosome. In a medium-sized metacentric pair (no. 8), there was secondary constriction at the proximal region of short arms as shown with an arrow (Fig. 3A). The autosome pairs of nos. 4 and 8 had small centromeric C-bands; the short arms of pairs nos. $3,8,10,11,15$, and 17 were entirely heterochromatic; telomeric C-bands were detected either on the short arm or the long arm, or on both arms of pairs nos. 2-4, 8, 13-16, and X chromosome; the long arms of Y chromosome was heterochromatic (Fig. 3C)

G-band comparison detected chromosome pair matching between D. pernyi and D. pyrrhomerus (Fig. 4). We found that $D$. pernyi no. 18 long arm and no. 13 long arm 
A

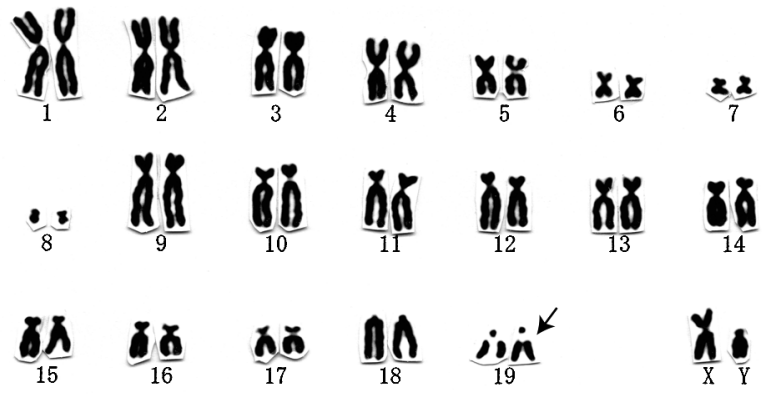

B

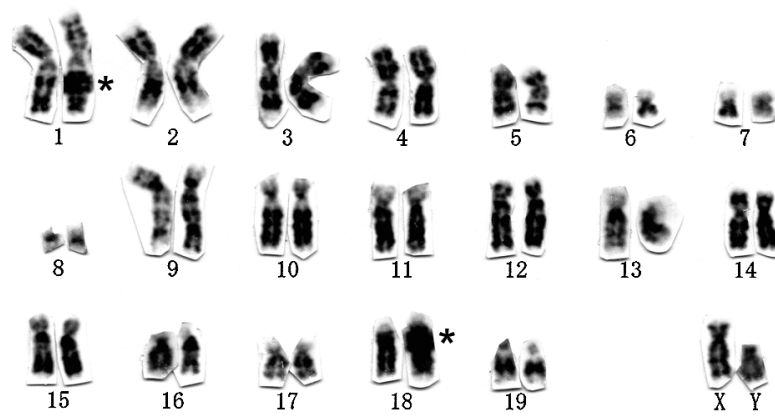

C

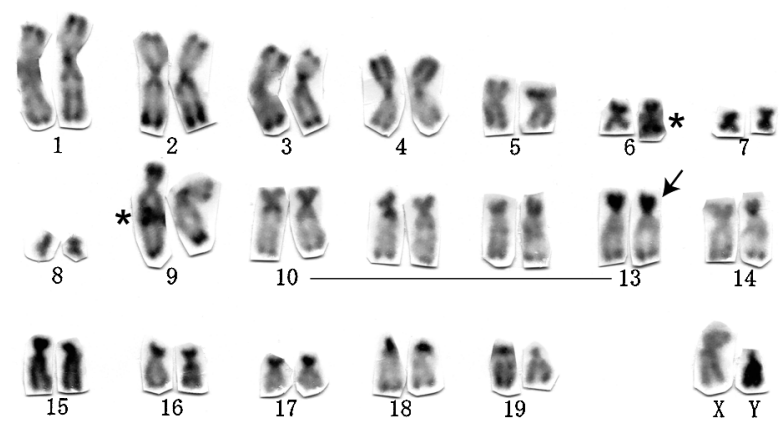

Fig. 2. Conventionally stained (A), G-banded (B), and C-banded (C) karyotypes of Dremomys pernyi from China. Arrows indicate the secondary constriction (B) and heterochromatic arm (C). Asterisks show the overlapping of chromosome arms.

correspond to D. pyrrhomerus no. 5 long arm and short arm, respectively (Fig. 4, indicated in box). Dremomys pernyi no. 19 long arm corresponded with $D$. pyrrhomerus no. 8 long arm, while we could not detect the homology of $D$. pyrrhomerus no. 8 short arm. Meta- or submetacentric $D$. pernyi no. 8 pair corresponded with acrocentric $D$. pyrrhomerus no. 18 pair; and subtelocentric $D$. pernyi no. 11 pair corresponded with metacentric D. pyrrhomerus no. 3 pair; while detailed chromosome rearrangements could not be detected in these pairs.

\section{Discussion}

Dremomys pernyi was originally described from Mouping (currently Baoxing) in Sichuan Province, China,
A

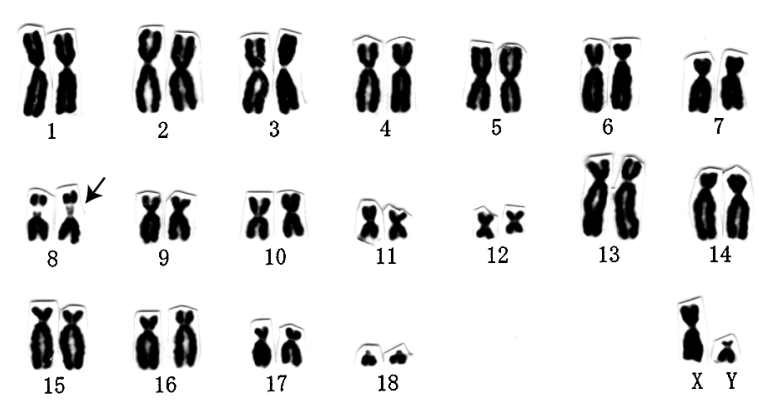

B

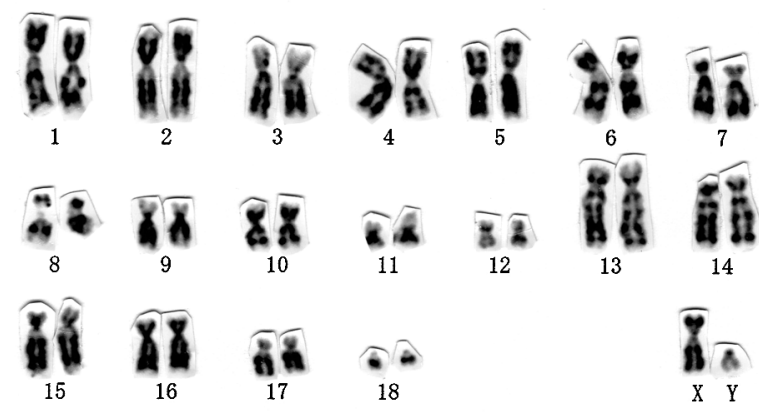

C

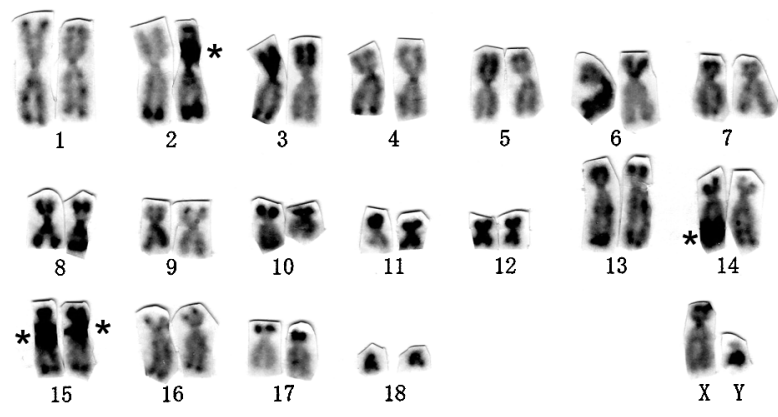

Fig. 3. Conventionally stained (A), G-banded (B), and C-banded (C) karyotypes of $D$. pyrrhomerus (B) from China. Arrow indicates the secondary constriction. Asterisks show the overlapping of chromosome arms.

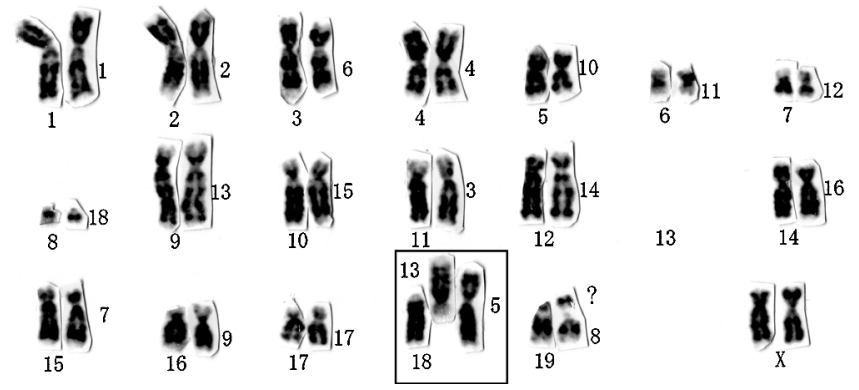

Fig. 4. G-band matching between D. pernyi (left) and D. pyrrhomerus (right).

and it is distributed in northeast India, north Burma, north Vietnam, and south China including Taiwan (Thorington and Hoffmann 2005). The collection site of the present 
study, Kangding, is less than $100 \mathrm{~km}$ from the type locality (Fig. 1). The karyotypes of $D$. pernyi from Kangding was $2 \mathrm{n}=40$ and $\mathrm{FNa}=72$, and from Yunnan (as subspecies $D$. pernyi flavior; $2 \mathrm{n}=40$ and $\mathrm{FNa}=70$ ) reported by Wang et al. (1980) have same 2n, but different FNa. Such chromosome difference was due to the number of medium-sized acrocentric pairs: two pairs in Kanding and three pairs in Yunnan. Further study is necessary for precise understanding of this geographic chromosomal variation.

The present karyotype is, however, different from the karyotype of the conspecific Taiwan population carrying $2 \mathrm{n}=38$ and $\mathrm{FNa}=68$ (Oshida et al. 2003). In addition to the differences in $2 \mathrm{n}$ and $\mathrm{FNa}$, an acrocentric pair from Kanding had secondary constriction on proximal part of long arm (Fig. 2A, no. 19), while the similar sized acrocentric pair from Taiwan had secondary constriction on the proximal part of short arms with developing satellite on the terminal region of short arms (Oshida et al. 2003, no. 17). The heterochromatic short arms of a subtelocentric pair exist in the former (Fig. 2C, no. 13), while they are absent in the latter (Oshida et al. 2003). Although we could not directly compare G-band patterns between karyotypes from Kangding and Taiwan, karyological differences with different $\mathrm{FNa}$ values are not responsible for Robertsonian rearrangements, and more complicated chromosome rearrangements of above-mentioned and of possible additional tandem fusions/fissions might have established postmating cytological reproductive isolation (King 1993) between the two populations. The karyotype of $D$. pernyi in this study is from very close to the type locality and could be considered representative of the species. The Taiwan population has sometimes been considered a distinct subspecies, D. p. owstoni, which was originally described from Mt. Alishan in Taiwan (Thomas 1908). In this paper, we suggest the Taiwan population to be recognized a distinct species $D$. owstoni from $D$. pernyi, and further morphological analysis to verify the distinctness between $D$. pernyi and $D$. owstoni will be conducted.

To our knowledge, this is the first report of the karyotype of $D$. pyrrhomerus. It resembles the karyotype of $D$. rufigenis from Vietnam with $2 \mathrm{n}=38$ (Nadler and Hoffmann 1970), but there are some differences in conventionally stained karyotypes between two species in this study in addition to different interpretation for the numbers of M/SM, ST, and A (Table 1). Difference in FNa (70 in D. pyrrhomerus and 68 in D. rufigenis) is likely to be related to the possible chromosomal rearrangement between medium-sized metacentric pair with a secondary constriction (no. 8) in D. pyrrhomerus and the acrocentric pair developing secondary constriction on the proximal part of short arms and prominent satellite on terminal region of short arms in D. rufigenis reported by Nadler and Hoffmann (1970). Dremomys rufigenis has been considered a sister species of $D$. pyrrhomerus based on the mitochondrial cytochrome $b$ gene phylogeny (Li et al. 2008) and similarity in skull morphometrics (Li 2010). In the past, $D$. pyrrhomerus was sometimes considered conspecific with D. rufigenis (e.g., Corbet and Hill 1992); but the two species showed mostly separate but close distributions involving sympatric localities (Zhang et al. 1997; Thorington and Hoffmann 2005). This study may suggest the occurrence of reproductive isolation between the two species due to chromosomal rearrangement; and future study for G-band and C-band karyotypes for $D$. rufigenis is expected for detailed comparison between these two species.

G-band and C-band comparisons between D. pernyi and $D$. pyrrhomerus showed well matching of homologous arms. Notable chromosome rearrangements were found between $D$. pernyi nos. $13 / 18$ pairs and $D$. pyrrhomerus no. 5 pair. We suggest that $D$. pernyi karyotype might have been derived from the karyotype similar to D. pyrrhomerus, with the Robertsonian fission of D. pyrrhomerus no. 5 pair, producing $D$. pernyi nos. 13 and 18 pairs; and subsequent heterochromatin addition in D. pernyi no. 13 pair to form short arms. Future studies

Table 1. Karyotype composition of Dremomys species

\begin{tabular}{|c|c|c|c|c|c|c|c|c|}
\hline \multirow{2}{*}{ Species } & \multirow{2}{*}{$2 n$} & \multirow{2}{*}{$\mathrm{FNa}$} & \multicolumn{3}{|c|}{ Autosomal pair } & \multirow{2}{*}{$X$} & \multirow{2}{*}{$\mathrm{Y}$} & \multirow{2}{*}{ Reference } \\
\hline & & & $\mathrm{M} / \mathrm{SM}$ & ST & A & & & \\
\hline D. pernyi (Sichuan) & 40 & 72 & 8 & 9 & 2 & SM & ST & This study \\
\hline D. pernyi (Yunnan) & 40 & 70 & 8 & 8 & 3 & $\mathrm{SM}$ & $\mathrm{SM}$ & Wang et al. (1980) \\
\hline D. pernyi (Taiwan) & 38 & 68 & 7 & 9 & 2 & $\mathrm{SM}$ & A & Oshida et al. (2003) \\
\hline D. pyrrhomerus (Guangdong) & 38 & 70 & 12 & 5 & 1 & SM & ST & This study \\
\hline D. rufigenis (Vietnam) & 38 & 68 & 9 & 7 & 2 & SM & SM & Nadler and Hoffmann (1970) \\
\hline
\end{tabular}


for G-band and C-band karyotypes for other Dremomys species including $D$. owstoni in Taiwan are expected to explore detailed chromosome evolution in the genus Dremomys.

Acknowledgments: This study was supported by grants from the NSFC Major International (Regional) Joint Research Project Grant (No. 31110103910), JSPS Core-toCore Program B. Asia-Africa Science Platforms, and JSPS Grant-in-Aid for Scientific Research (No. 26304009). We thank two anonymous reviewers for useful comments to improve the manuscript.

\section{References}

Corbet, G. B. and Hill, J. E. 1992. The Mammals of the Indomalayan Region: A Systematic Review. Oxford University Press, Oxford, $488 \mathrm{pp}$.

Harada, M. and Yosida, T. H. 1978. Karyological study of four Japanese Myotis bats (Chiroptera, Mammalia). Chromosoma 5: 283291.

Hoffmann, R. S. and Smith, A. T. 2008. Family Sciuridae. In (Smith, A. T. and Xie, Y., eds.) A Guide to the Mammals of China, pp. 172 196. Princeton University Press, Princeton.

King, M. 1993. Species Evolution; The Role of Chromosome Change. Cambridge University Press, Cambridge, $336 \mathrm{pp}$.

Levan, A., Fredga, K. and Sandberg, A. A. 1964. Nomenclature for centromeric position on chromosomes. Hereditas 52: 201-220.

Li, S. 2010. A cladistic phylogeny of the plain long-nosed squirrels (Sciuridae, Dremomys) from the mainland of southeastern Asia based on morphological data. Acta Theriologica Sinica 30: 119126.
Li, S., Yu, F., Yang, S., Wang, Y., Jiang, X., McGuire, P. M., Feng, Q. and Yang, J. 2008. Molecular phylogeny of five species of Dremomys (Rodentia: Sciuridae), inferred from cytochrome $b$ gene sequences. Zoologica Scripta 37: 349-354.

Nadler, C. F. and Hoffmann, R. S. 1970. Chromosomes of some Asian and South American squirrels (Rodentia: Sciuridae). Experientia 26: $1383-1386$.

Oshida, T., Lee, J. K., Yuan, S. L. and Lin, L.-K. 2003. A preliminary note on banded karyotypes of the Perny's long-nosed squirrel Dremomys pernyi (Mammalia, Rodentia) from Taiwan. Caryologia 56: 171-174.

Seabright, M. 1971. A rapid banding technique for human chromosomes. Lancet 2: 971-972.

Sumner, A. T. 1972. A simple technique for demonstrating centromeric heterochromatin. Experimental Cell Research 75: 304-306.

Thomas, O. 1908. On the generic position of the groups of squirrels typified by "Sciurus" berdmorei and pernyi. Journal of Bombay Natural History Society 18: 244-249.

Thorington, R. W., Jr. and Hoffmann, R. S. 2005. Family Sciuridae. In (Wilson, D. E. and Reeder, D. M., eds.) Mammal Species of the World: A Taxonomic and Geographic Reference Third edition, pp. 754-818. The Johns Hopkins University Press, Baltimore.

Thorington, R. W., Jr., Koprowski, J. L., Steele, M. A. and Whatton, J. F. 2012. Squirrels of the World. The Johns Hopkins University Press, Baltimore, 459 pp.

Wang, Y., Li, S., Li, C., Wang, R. and Liu, G. 1980. Karyotypes and evolution of three species of Chinese squirrels (Sciuridae Mammalia). Zoological Research 1: 501-521 (in Chinese with English abstract).

Zhang, R., Jin, S., Quan, Q., Li, S., Ye, Z., Wang, F. and Zhang, M. 1997. Distribution of Mammalian Species in China. China Forestry Publishing House, Beijing, 280 pp.

Received 26 July 2015. Accepted 5 October 2016. Editor was Tatsuo Oshida. 